\title{
Employment Expectation Profiles as a \\ Differential Measure of Employment-Relevant Attitudes Towards People with Disabilities
}

Michael J. Millington

David Rosenthal

Alan Lott Jr.

Abstract - The ability of the Employment Expectation Questionnaire-Beta version (EEQ-B) to differentially describe employment relevant attitudes towards people with disabilities was investigated. Labels of cognitive disability and gender were manipulated in an analog study. Respondents from a convenience sample of students read stimulus material concernin a job and job applicant and then rated the applicant's qualification for the job. A significant effect was found for disability but not for gender or interaction effects. Post hoc contrasts suggest that labels of cognitive disability (mental retardation, menta illness, and traumatic brain injury) had a differential effect across the factors of the EEQ-B.

$\mathrm{T}$ value of researching attitudes towards workers with disabilities is predicated on the following assumptions: (a) Employment-relevant attitudes can be identified, described, and measured; (b) the attitudes of significant others can mediate employment outcomes for people with disability; and (c) counselor efforts can effect positive change in employment-relevant attitudes. The study of employment-relevant attitudes towards people with disabilities has been a vital point of professional inquiry for several decades (Greenwood \& Johnson, 1987). Employer attitudes are thought to be of particular value, given the potential amount of control they possess over employment outcomes (Levy, Jesop, Rimmerman, Francis, \& Levy, 1993; Millington, Szymanski, \& Hanley-Maxwell, 1994). Yet relevant attitudes remain difficult to define (Diksa \& Rogers, 1996), measure (Schmelkin, 1988), and, consequently, to change (Greenwood \& Johnson, 1987).

The productive study of attitudes towards people with disabilities, has been a challenge to investigators (Millington, Strohmer, Reid, \& Spengler, 1996; Yuker, Block, \& Campbell, 1960) for decades. Often, the subject of research are attitudes perse, with behavion, cognitive, and resective are attitudes perse, with behavioral, cognitive, and affective aspects of attitudes receiving less attention (Grand, Bernier, Strohmer, 1982; Marinelli, 1974; Millington et al., 1996). Generally, attudes towards people with disabilities are thought to be complex and differentiated by disability category (Fuqua, Rathbun, \& Gade, 1984), severity (Weller \& and context (Gordon, Minnes, \& Holden, 1990; Grand et al.
1982). But descriptive knowledge of attitudes without refrence to subsequent cognition and behaviors ignores the motive for studying the construct in the first place: Attitudes are thought responsible for bias in decision-making proce ies for studying dischility attitudes must identify releveeres for studying disability attitudes must identify relevant ttitudes by context, and attempt to link them to process an omes.

In the context of the workplace, employment expectation may provide a more utilitarian conceptualization of employment-relevant attitudes. Where attitudes tend to be contexree generalized value statements (e.g., cosmetic aversion, net affect; Kohler \& Graves, 1973), expectations are conext-specific prediction of behavioral outcomes (e.g., reliability, social integration; Millington et al., 1994). Attitudes shape expectations (Gordon et al., 1990), which are realized in the criteria of employment selection. Thus expectation are a surface representation of underlying attitudes that have the advantage of being tied to observable and measurable behaviors.

Millington et al.(1994) conceptualized employment expectations as predictions of job relevant behavior used by mployers as criteria of screening and hiring new employes. In employment selection the goal of the employer is to gequire the most desirable worker. From the employer perpective, the most desirable worker is the one who will minimize cost and maximize productivity (Millington, Asner, Linkowski, \& Der-Stepanian, 1996). Screening criteria
are behaviors associated with worker cost to the organizathe organization. The employer's challenge is to use these criteria to predict which applicant will provide the most profitable mix of work-relevant behaviors.

Millington, Reid, and Leierer (1997) suggest that a large number of work relevant behaviors are possible criteria of selection, but that these behaviors group around a much smaller set of factors, and that these factors provide the structure for employer decision-making. The authors have identified five factors including: (a) Job knowledge/production skills, the knowledge, skills, and abilities a worker has, or develops on the job, that effect ability to get the job done or develops on the job, that effect ability to get the job done: (b) socialization and emotional coping skills, the social skills the worker has that effect ability to get along with coworkers trainability/task flexibility, the academic and thinking skills a worker has that effect ability to learn new skills, and be iors that demonstrate accountability for time-on-task; and (e) motivation/satisfaction, the behaviors that indicate commitment to and satisfaction with work. While the factors surfaced are non-inclusive and strictly preliminary, there is some empirical and theoretical support for their role in employment selection (Bills, 1988; Bluestone, 1989; Christman \& Slaten, 1991; Krefting \& Brief, 1977; Pooley \& Bump, 1993). This model for investigating employmentrelevant attitudes suggests that disability-related attitudes may be differentiated across the factors of selection; that attitudes should be definable in terms negative or positive distortions of expectations; and that distortions in expectation profiles may result in biased employment outcomes. This study is a continuation of the analysis initiated in Millington et al. (1997). Whereas the previous analysis identified potential factors of employment selection, this analysis addresses the descriptive nature of expectation profiles. In this study we examine the effect of cognitive disability labels and gender on expectation profiles.

\section{Method}

Experimental, postmeasure-only and descriptive post hoc elements were included in the research design (Pedhazur \& Schmelkin, 1991) to address the following research hypothesis: Labels of cognitive disability and gender will have a differential effect on employment expectation profiles.

The independent variables were gender (male, female) and cognitive disability label status, a categorical variable with four levels: No label (control), mental retardation (MR), mental illness (MI), and traumatic brain injury (TBI). The dependent variables were factor scale scores making up the employment expectation profile from the employment expectation questionnaire-beta version (EEQ-B). These continuous variables were described as: (a) Acquired job competencies, socio-emotional coping skills, general educational development, dependability, and motivation. Good internal consistency was reported for the factor based scores with Chronbach's alphas ranging from .94 to .87 .

A convenience sample derived from college students ttending three mid-western universities was generated. Respondents were recruited by flyers posted on campus, and hrough personal contacts made by the researchers. A total of 323 completed questionnaires were returned. After removing outliers (Tabachnik \& Fidell, 1983), 319 questionnaires were deemed suitable for analysis. The median age of the sample was 22 years, ranging from 18 to 56 years. The sample was predominately female $(74 \%)$, Caucasian $(91 \%)$, and identified as not having a disability (92\%). Respondents were randomly assigned to one of eight treatment combinations (disability label X o one of

An analog study was employed, in which the respondents An the role of a restaurant man in hiring a he Diction for D (D.OT 318.687-010). A fictitious of a dishcribing ant, 318.687 for the job of dishwater cibing applicant for the job of dishwasher was "Pat", a job applicant, in which gender and disability label status were manipulated. After reading the narrative, the respondents were directed to evaluate the applicants' qualification using the EEQ-B. Stimulus material is available for perusal (Millington et al., 1997).

Results

A completely crossed factorial MANOVA was used to test the null hypotheses negating disability, gender, and disability $\mathrm{X}$ gender interaction effects. Prior to subjecting the factor based scores to parametric multivariate analysis, statistical assumptions were tested. Computed z-scores for kewness and kurtosis ( $\mathrm{z}>$ critical value |1.96I) were not significant, suggesting acceptable normality. The multivariate assumption of homogeneity of dispersion was not rejected (Box's $M=70.95 ; p>.001$ ).

The combined effect of the dependent variables were significant for disability label status $(\mathrm{F}[3,311]=3.17$, $\mathrm{p}<$ $.001)$, but not for gender $(F[1,311]=0.47, p>.05)$. or for abel $x$ gender interaction $(F(3,311)=0.45, p>.05)$. Thus only the null hypothesis for disability label status, "The centroid of the linear composite of factor scores does not differ based on group disability label status," was rejected. Joint-univariate contrasts were run on label status for each factor as a post-hoc exploration of the difference between label groups (see Table 1). Simple contrasts comparing means of the three disability label groups with the control group mean were performed.

A Bonferroni technique was used to control for inflation error. Effects are suggested in expectations for socio-emotional coping skills and general educational development in the mental retardation label group; for socio-emotional coping, dependability, and motivation expectations for the mental illness label group, and motivation expectations for the traumatic brain injury label group. 


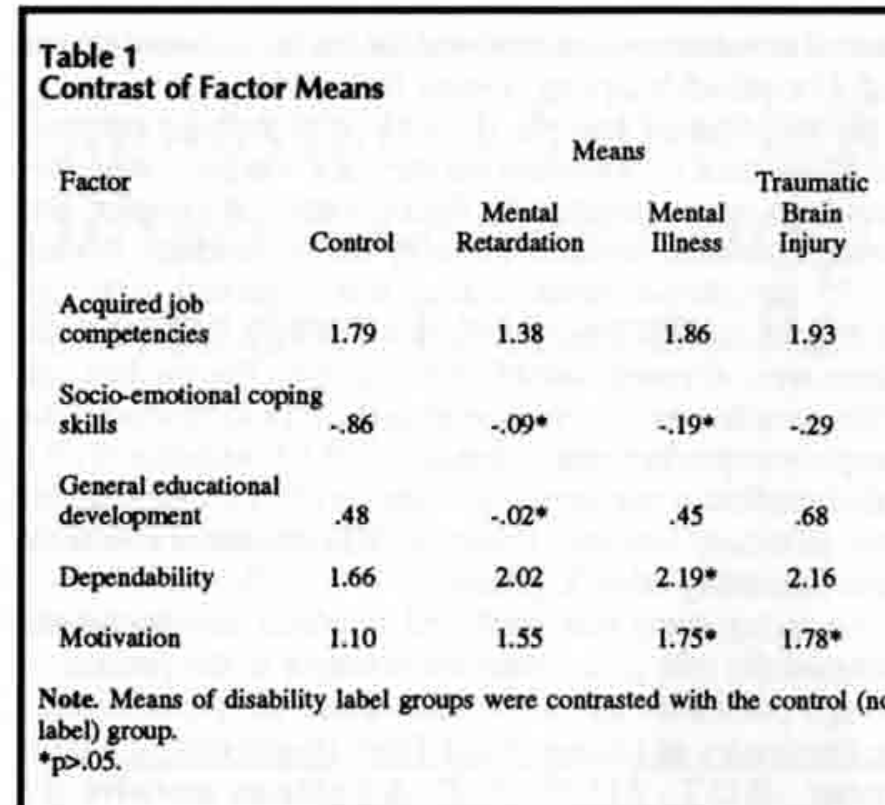

\section{Discussion}

The primary purpose of this study was to demonstrate how contextually relevant attitudes towards people with disabilities and gender may be expressed and measured in the criteria of employment selection. To this end, labels of cognitive disability and gender were used to generate a biasing effect in the evaluation of applicant qualification. In this pilot study, the employment expectation profiles provided by the EEQ-B did not reveal a gender effect, but a small though significant effect for disability labels status overall evaluations. The EEQ-B profiles also provided descriptive differences between labels, when compared to the control group. These preliminary findings suggest that the EEQ-B employment expectation profiles may provide useful information in future examinations of the effect of disability information on exper attitudes in the context employment selection. Further interpretation of the results must be constrained by the is helpful for the development of the pilot study, but the results cannot be generalized to employers or other stakeholder groups. However, findings of this study may be interpreted as speculative hypotheses concerning employer expectations that will require further investigation with a more meaningful sample.

A closer inspection of the contrasted means provides some interesting illustrations of the differences engendered by disability labels. The MR label group rating was significantly more qualified in socio-emotional coping skills, and significantly less qualified than the control group in general educational skills. The MI label group rating was significantly more qualified in both socio-emotional coping skills, dependability, and motivation than the control group. The TBI label group rating was significantly more qualified in motivation than the control group. In this study, most of the bias introduced by labels favored the applicant with a $\operatorname{cog}$ nitive disability. There are several potential explanations for these findings. First, the information contained in the label may be interacting with information contained in the stimulus material. The control groups consistently low ratings in dependability, motivation, and socio-emotional copin skills suggests that disability labels created a positive halo effect (Nisbett \& Wilson, 1977), dampening the impact of negative information imbedded in the stimulus material. Second, the findings may be related to the nature of the sample. Given that the sample was drawn from rehabilitation counseling programs as well as generally through the cam pus, it is possible that the effect is due in part to a bias of professional advocacy. While still other possible explanations exist, these findings suggest that disability status may engender positive or negative attitudes, in complex combinations. Whether or not these polar tendencies have a similarly differentiated effect on employment outcomes is, perhaps the most intriguing question left for future attitude research.

The EEQ-B is the current iteration of a pilot instrument that attempts to identify and describe stakeholder expectaons in employment performance outcomes. Expectation re often potent precursors to success or failure in soci ind inclions work. The expectations of both workers encer

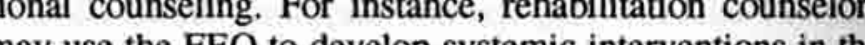

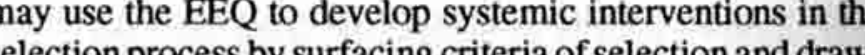
ectionprocess by surfacing criteria of selectionand drawing attention to potential bias; or as a means to identify an descents work dence between worker and employer perceptions of worker detisfactoriness. Potential utility and promising findings hus far suggest that further development and refinement the EEQ-B is warranted.

\section{References}

Bills. D. (1988). Credentials and capacities: Employers' pereptions of the acquisition of skills. The Sociological Quarterly, 29, 439-449.

Bluestone, B. (1989). Employment prospects for persons with industry, and disability (pp. 17-25). Baltimore: Brookes.

Bordieri, J., \& Drehmer, D. (1987). Attribution of responsibityation Counseling Bulletin, 30, 218-226.

Christman L \& Slaten, B (1991). Attitudes toward peop with disabilities and judgements of employment potential. Perceptual and Motor Skills, 72, 467-475.

Diksa, E., \& Rogers, E. S. (1996). Employer concerns abou iring persons with psychiatric disability: Results of the employer

Fuqua, D., Rathbun, M., \& Gade, E. (1984). A comparison of disabled workers. Journal of Applied Rehabilitation Counseling 15(1), 40-41.
Gordon, E., Minnes, P., \& Holden, R. (1990). The structure of ttitudes toward persons with a disability, when specific disability and context are considered. Rehabilitation Psychology, 35, 79-90 Grand, S. A., Bernier, J. E., Strohmer, D. C. (1982). Attitudes
oward disabled persons as a function of social context and specific disability. Rehabilitation Psychology, 27, 165-174

Grenwood, R., \& Johnson, V. (1987). Employer perspectives on wo

Kohler, E., \& Graves, W. H. (1973). Factor analysis of the
Disability Factor Scales with the Little Jiffy. Mark III. Rehabiliation Psychology, 20, 102-107.

Krefting, L., \& Brief, A. (1977). The impact of applican disability on evaluative judgements in the selection process. Acad my of Management Journal, 19, 675-680.

Levy, J., Jesop D., Rimmerman, A., Francis, F., \& Levy, P. owards the employment of persons with severe handicaps. Journal of Rehabilitation, 59, 49-54.

Marinelli, R. P. (1974). State anxiety in introductions with visibly

Millington, M. J., Asner, K. K., Linkowski, D. C. \& DerMillington, M. J., Astr, K K., Lin ness perspective. In E. Szymanski, \& R. Parker (Eds.), Work and Disability (pp. 277-308). Austin TX: PRO-ED

Millington, M. J. Reid, C., Leierer, S. (1997). Employmen expectations in rehabilitation counseling: Factors of employmen Millingto M. J Stom, (1996). A preliminary investigation of the role of differentia complexity and response style in measuring attitudes towads people with disabilities. Rehabilitation Psychology, 41, 243-254.
Millington, M. J., Szymanski, E. M., \& Hanley-Maxwell, C. (1994). The effect of the label of mental retardation on employer $27-43$. Nisbett, R. E., \& Wilson, T. D. (1977). Telling more than can know: Verbal reports on mental processes. Psychological Review, 84, 231-259.

design and, E. J., \& Schmelkin, L. P. (1991). Measurement, design, and analysis: An integrated approach. Hillsdale, NJ:
Lawrence Errbaum Associates. Pooley, J. M., \& Bump, E. A.(1993). The learning performance and cost effectiveness of mentally disabled workers. Group \& Organization Management 18(1), 88-102.

Schmelkin, L. P. (1988). Multidimensional perspectives in the perception of disabilities. In H. E. Yuker (Ed.), A Tabachnik, B. G., \& Fidell, L. S. (1983). Using multivariate

Weller, L., \& Aminadave, C. (1989). Attitudes towards mild and severe handicap in Israel. British Journal of Medical Psychology, 62, 273-280.

Yuker, H., Block, J., \& Campbell, W. (1960). A scale to Human Resources Center.

Michael J. Millington, Ph.D., Louisiana State University Medical Center, New Orleans, LA.

David Rosenthal, Ph.D., Pennsylvania State University, College Park, PA.

Alan Lott, Ir., Alabama University, Auburn, AL. 